\title{
PENGARUH SLOW DEEP BREATHING TERHADAP TEKANAN DARAH LANSIA HIPERTENSI DI PUSKESMAS UBUNG LOMBOK TENGAH
}

\author{
Ni Putu Sumartini ${ }^{1}$, Ilham Miranti ${ }^{2}$ \\ ${ }^{1,2}$ Jurusan Keperawatan, Poltekkes Kemenkes Mataram, Indonesia
}

\begin{abstract}
Abstrak
Hipertensi menjadi silent killer karena sebagian besar kasus tidak menunjukkan gejala apapun. Hipertensi terus meningkat seiring bertambahnya umur. Penemuan kasus Hipertensi di Puskesmas Ubung meningkat dimana tahun 2016 ditemukan 931 kasus dan tahun 2017 ditemukan 1.240 kasus hipertensi. Lansia yang mengalami hipertensi sebanyak 805 orang. Pengobatan non farmakologi bisa didapatkan dengan melakukan slow deep breathing, selain dengan olahraga atau senam dan mengkonsumsi obat-obatan dapat memberikan keterampilan pada pasien dalam mengatasi tekanan darah pada pasien hipertensi. Tujuan: Tujuan penelitian ini adalah untuk mengetahui pengaruh slow deep brething terhadap tekanan darah lansia hipertensi. Metode: Jenis penelitian ini adalah kuantitatif, metode penelitian Quasy Experiment dengan desain Non Equivalent Control Group. Sampel dalam penelitian ini adalah lansia hipertensi yang mendapat senam. Jumlah sampel dalam penelitian ini adalah 30 orang dengan teknik pengambilan sampel menggunakan purposive sampling. Instrument penelitian menggunakan lembar observasi tekanan darah. Teknik pengolahan data dalam penelitian ini menggunakan uji Paired T-test. Hasil: Hasil Penelitian menunjukkan rata-rata tekanan darah sistol kelompok intervensi sebelum diberi perlakuan sebesar $151,33 \mathrm{mmHg}$ dan diastol sebesar $96,00 \mathrm{mmHg}$ dan sistol kelompok intervensi sesudah diberi perlakuan sebesar $136,00 \mathrm{mmHg}$ dan diastol sebesar $85,33 \mathrm{mmHg}$ dengan nilai signifikansi sistol ( $\rho$ value) 0.000 dan diastol ( $\rho$ value) 0.000 sehingga $H_{o}$ ditolak. Kesimpulan: Kesimpulan menunjukan adanya pengaruh slow deep breathing terhadap tekanan darah lansia hipertensi di Puskesmas Ubung Lombok Tengah.
\end{abstract}

Kata Kunci : lansia, hipertensi, slow deep breathing

\section{EFFECT OF SLOW DEEP BREATHING ON BLOOD PRESSURE OF ELDERLY WITH HYPERTENSION IN PUSKESMAS UBUNG, CENTER OF LOMBOK}

\begin{abstract}
Hypertension is known as the silent killer because most cases show no early symptoms. Hypertension continuously increases further with age. Hypertension case finding in Puskesmas (Public Health Centre) Ubung increased, in 2016 found 931 cases and in 2017 found 1,240 cases of hypertension. Hypertension in elderly individuals are 805 people. Non-pharmacological treatment can be obtained by doing slow deep breathing, in addition of sport or exercises and consumed drugs, are able to improve skills of patients to solve their Hypertension. This research aimed to know the influence of slow deep breathing on blood pressure of elderly hypertension. This research was quantitative study, Quasi-Experimental research method with Non-Equivalent Control Group Design. The sample in this study was elderly Hypertension who participated in gymnastic programme. The number of samples in this study were 30 people with sampling technique using purposive sampling. The research instrument used a blood pressure observation sheet. Data processing methods in this study using Paired T-test. The results showed an average of systole blood pressure in the intervention group before treatment
\end{abstract}


was $151,33 \mathrm{mmHg}$ and diastole was $96,00 \mathrm{mmHg}$ and systole of intervention group after treated with $136,00 \mathrm{mmHg}$ and diastole equal to $85,33 \mathrm{mmHg}$ with systole significance value ( $\rho$ value) 0.000 and diastole ( $\rho$ value) 0.000 so $\mathrm{H}_{\mathrm{o}}$ is rejected. This research shows the effect of slow deep breathing on blood pressure of elderly hypertension in Puskesmas Ubung, Center of Lombok.

\section{Keywords: elderly, hypertension, slow deep breathing}

\section{PENDAHULUAN}

Hipertensi adalah suatu keadaan dimana seseorang mengalami peningkatan tekanan darah di atas normal, baik tekanan sistolik dan atau diastolik (Triyanto, 2014 dalam Azizah, 2015). Hipertensi atau tekanan darah tinggi adalah peningkatan tekanan darah sistolik lebih dari $140 \mathrm{mmHg}$ dan tekanan darah diastolik lebih dari $90 \mathrm{mmHg}$ pada dua kali pengukuran dengan selang waktu lima menit dalam keadaan cukup istirahat/tenang (Kementerian Kesehatan RI, 2014). Hipertensi menjadi silent killer karena pada sebagian besar kasus tidak menunjukkan gejala apapun hingga pada suatu hari hipertensi menjadi stroke dan serangan jantung yang mengakibatkan penderitanya meninggal. Bahkan sakit kepala yang sering menjadi indikator hipertensi tidak terjadi pada beberapa orang atau dianggap keluhan ringan yang akan sembuh dengan sendirinya (Kurniadi \& Ulfa, 2015). Seiring bertambahnya umur, tekanan darah akan meningkat terutama tekanan darah sistolik, sedangkan tekanan darah diastolik pada mulanya meningkat, tetapi pada usia pertengahan akan menetap atau akan menurun sejalan dengan pengerasan pembuluh darah (Kurniadi \& Ulfa, 2015).

Proporsi dari populasi penduduk berusia lebih dari 60 tahun adalah 11,7\% dari total populasi dunia secara global pada tahun 2013, dan diperkirakan jumlah tersebut akan terus meningkat seiring dengan peningkatan usia harapan hidup. Penelitian di Amerika Serikat menemukan bahwa tekanan darah sistolik meningkat sejalan dengan bertambahnya usia, tetapi tekanan darah diastolik meningkat hanya sampai usia 55 tahun (Kurniadi \& Ulfa, 2015). Prevalensi hipertensi di Indonesia pada golongan umur 50 tahun masih $10 \%$, tetapi diatas 60 tahun angka tersebut terus meningkat mencapai $20-30 \%$. Berbagai penelitian melaporkan bahwa 1,3-28,6\% penduduk diatas 20 tahun adalah penderita hipertensi (Kurniadi \& Ulfa, 2015). Prevalensi hipertensi pada usia kurang dari 31 tahun 5\%, usia antara 31-44 tahun 8-10\%, usia lebih dari 45 tahun sebesar 20\% (Kurniadi \& Ulfa, 2015). Berdasarkan pengukuran tekanan darah lansia hipertensi di Indonesia dihitung dari umur 55-64 tahun 20,5\%, umur 65-74 tahun $26.4 \%$ dan umur 75 ke atas sebesar 27.7\%, sedangkan di NTB dihitung dari umur 55-64 tahun 44.8\%, umur 65-74 tahun 57.2\% dan umur 75 ke atas sebesar 65.4\% (RISKESDAS, 2013). Data yang diperoleh dari Dikes Lombok Tengah semester 1 tahun 2017, dari 10 penyakit tertinggi di Lombok Tengah, hipertensi menepati peringkat kedua dengan jumlah kasus sebanyak 5005 kasus (Dinkes Kab. Lombok Tengah, 2017). Berdasarkan data yang diperoleh dari Puskesmas Ubung tahun 2016 terdapat 931 kasus penderita hipertensi, sedangkan pada tahun 2017 terjadi peningkatan dengan jumlah kasus 1.240. Lansia yang mengalami hipertensi sebanyak 805 orang. Hasil studi pendahuluan 
yang dilakukan peneliti, di Puskesmas Ubung sudah melakukan tindakan atau upaya untuk menurunkan penyakit hipertensi, salah satunya adalah program senam. Lansia yang mengikuti senam, dari 25 orang lansia semua mengalami hipertensi dengan rata-rata tekanan darah sistolik 165,6 $\mathrm{mmHg}$ dan diastolik 103,6 mmHg.

Penyebab hipertensi dibagi menjadi dua, yaitu hipertensi esensial atau primer dan hipertensi sekunder. Beberapa faktor resiko yang dapat menyebabkan terjadinya tekanan darah tinggi yaitu dibedakan menjadi dua kelompok yang terdiri dari faktor resiko yang tidak dapat di kendalikan seperti usia, jenis kelamin, etnis/ras dan keturunan sedangkan faktor resiko yang dapat dikendalikan yaitu kegemukan, stres, merokok, kurang olahraga, konsumsi alkohol, konsumsi garam berlebihan, dan kolesterol (Depkes RI, 2006). Hipertensi dapat menjadi ancaman serius bila tidak ditangani. Tekanan darah tidak terkontrol akan mengakibatkan stroke, infark miokard, gagal ginjal, ensefalopati, dan kejang (Tambayong, 2010). Meningkatnya tekanan darah di dalam arteri bisa terjadi melalui beberapa cara yaitu jantung memompa lebih kuat sehingga mengalirkan lebih banyak cairan pada setiap detiknya, arteri besar kehilangan kelenturannya dan menjadi kaku sehingga mereka tidak dapat mengembang pada saat jantung memompa darah melalui arteri tersebut. Darah pada setiap denyut jantung dipaksa untuk melalui pembuluh yang sempit daripada biasanya dan menyebabkan naiknya tekanan darah. Inilah yang terjadi pada usia lanjut, dimana dinding arterinya telah menebal dan kaku karena arteriosklierosis (Triyanto, 2014). Penyempitan pembuluh darah akibat hipertensi dapat menyebabkan berkurangnya suplai darah dan oksigen ke jaringan yang akan mengakibatkan mikroinfark pada jaringan. Komplikasi berat hipertensi adalah kematian karena obstruksi dan rupturnya pembuluh darah otak (Price \& Wilson, 2006). Penderita mengalami komplikasi pada organ-organ vital seperti jantung, otak ataupun ginjal. Gejala-gejala akibat hipertensi, seperti pusing, gangguan penglihatan, dan sakit kepala, sering kali terjadi pada saat hipertensi sudah lanjut disaat tekanan darah sudah mencapai angka tertentu yang bermakna (Triyanto, 2014).

Hipertensi dapat dikendalikan dengan terapi non-farmakologi, seperti Slow Deep Breathing yang termasuk ke dalam latihan dan relaksasi (Sepdianto, Nurachmah, \& Gayatri, 2010). Slow Deep Breathing adalah relaksasi yang disadari untuk mengatur pernapasan secara dalam dengan lambat (Martini, 2006). Slow Deep Breathing adalah metode bernapas yang frekuensi napasnya kurang atau sama dengan 10 kali per menit dengan fase ekshalasi yang panjang (Breathesy, 2007). Pada saat relaksasi terjadi perpanjangan serabut otot, menurunnya pengiriman impuls saraf ke otak, menurunnya aktivitas otak, dan fungsi tubuh yang lain, karakteristik dari respon relaksasi ditandai oleh menurunnya denyut nadi, jumlah pernafasan dan penurunan tekanan darah (Potter \& Perry, 2006). Slow Deep Breathing berpengaruh terhadap modulasi sistem kardiovaskular yang akan meningkatkan fluktuasi dari interval frekuensi pernafasan dan berdampak pada peningkatan efektifitas barorefleks serta dapat berkontribusi terhadap penurunan tekanan darah (Sepdianto, Nurachmah, \& Gayatri, 2010). Yanti, (2016), melakukan penelitian Pengaruh Slow Deep Breathing Terhadap Tekanan Darah Pada Penderita Hipertensi Di Wilayah Kerja Puskesmas I Denpasar Timur, dengan memberikan latihan Slow Deep 
Breathing selama 21 hari 2 kali dalam sehari. Hasil penelitian diperoleh data ada pengaruh pemberian Slow Deep Breathing terhadap tekanan darah pada penderita hipertensi. Oleh karena itu, peneliti tertarik melakukan penelitian mengenai pengaruh slow deep breathing terhadap tekanan darah lansia hipertensi di wilayah kerja Puskesmas Ubung Lombok Tengah.

Tujuan umum penelitian ini adalah mengetahui pengaruh slow deep breathing terhadap tekanan darah lansia Hipertensi di Puskesmas Ubung Lombok Tengah. Tujuan khusus penelitian ini adalah Mengidentifikasi tekanan darah sebelum latihan slow deep breathing pada lansia hipertensi kelompok intervensi dan kelompok kontrol di Puskesmas Ubung Lombok Tengah. Mengidentifikasi tekanan darah setelah latihan slow deep breathing pada lansia hipertensi kelompok intervensi dan kelompok kontrol di Puskesmas Ubung Lombok Tengah. Menganalisis pengaruh slow deep breathing terhadap tekanan darah pada lansia hipertensi di Puskesmas Ubung Lombok Tengah.

\section{METODE}

Jenis penelitian ini adalah penelitian Quasy Experiment dengan rancangan Non Equivalent Control Group. Dalam penelitian ini, kelompok intervensi dan kelompok kontrol sama-sama dilakukan Pretest dan Post-test (Notoatmodjo, 2012). Peneliti melakukan pengukuran tekanan darah pada kelompok intervensi dan kelompok kontrol sebelum latihan (pre test). Pada kelompok intervensi diberikan latihan slow deep breathing sebanyak tiga (3) kali dalam kurun waktu 3 miggu, masing-masing 15 menit, kemudian diukur tekanan darahnya (post test) sedangkan kelompok kontrol mendapatkan perawatan sesuai program puskesmas dan diukur tekanan darahnya (post test) (Dimiter \& Phillip, 2003).

Populasi dalam penelitian ini adalah semua lansia hipertensi di Puskesmas Ubung Lombok Tengah sebanyak 805 lansia. Sampel dalam penelitian ini adalah lansia yang mendapat senam di Puskesmas Ubung Lombok Tengah dan terpilih sebagai sampel. Besar sampel sesuai dengan Sugiyono (2010) yang menyatakan bahwa untuk penelitian eksperimen dan kelompok kontrol, jumlah anggota sampel masing-masing 10 sampai dengan 20 maka jumlah sampel dalam penelitian ini adalah 30 orang terbagi kedalam kelompok perlakuan dan kelompok kontrol. Tehnik sampling yang digunakan adalah purposive sampling dengan kriteria inklusi : (1) tidak mengalami gangguan pendengaran dan bicara, (2) bersedia menjadi responden, (3) aktif mengikuti senam; sedangkan kriteria eksklusi dalam penelitian ini adalah : (1) terdapat komplikasi seperti gagal ginjal, gagal jantung dan asma, serta (2) mengalami krisis hipertensi.

Variabel independen atau variabel bebas dalam penelitian ini adalah slow deep breathing sedangkan variabel dependen adalah tekanan darah. Data yang dikumpulkan dalam penelitian ini terdiri atas data primer dan data sekunder. Data primer adalah tekanan darah lansia hipertensi sebelum dan setelah dilakukan latihan slow deep breathing. Data sekunder meliputi data karakteristik responden yaitu usia, jenis kelamin dan riwayat hipertensi keluarga; dan gambaran lokasi penelitian. Data primer dikumpulkan dengan melakukan pemeriksan tekanan darah menggunakan spigmomanometer aneroid 
merk one med, sedangkan data sekunder tentang karakteristik responden dikumpulkan dengan menggunakan lembar isian data responden yang diisi oleh peneliti sesuai dengan data yang diberikan oleh responden. Sedangkan data sekunder tentang gambaran umum lokasi penelitian yaitu Puskesmas Ubung Lombok Tengah dikumpulkan melalui studi dokumentasi dan wawancara.

Data dikumpulkan setelah mendapatkan ijin penelitian dari institusi terkait dan Komite Etik Poltekkes Kemenkes Mataram. Pengumpulan data dilakukan dengan cara mengumpulkan calon responden dan kemudian mensosialisasikan tentang penelitian yang akan dilakukan (tujuan, manfaat) pada saat kegiatan senam di Puskesmas dan mendata lansia hipertensi yang bersedia menjadi responden. Selanjutnya memberikan lembar persetujuan kepada lansia hipertensi dan membagi responden menjadi kelompok eksperimen dan kelompok kontrol. Peneliti selanjutnya menjelaskan prosedur penelitian kepada kedua kelompok. Peneliti mengisi lembar isian data karakteristik responden. Melakukan pre test dengan melakukan pengukuran tekanan darah pada responden. Setelah senam, kelompok eksperimen diberikan latihan slow deep breathing sebanyak 3 kali masing-masing selama 15 menit sedangkan kelompok kontrol mengikuti perawatan dari Puskesmas. Melakukan post test setelah 3 minggu pada kedua kelompok.

Pengelolaan data dilakukan dengan memeriksa kembali semua lembar isian data responden dan lembar observasi tekanan darah untuk menghindari kemungkinan kuesioner belum lengkap diisi. Data yang terkumpul kemudian dimasukkan ke dalam master table. Analisis data untuk perubahan tekanan darah pada lansia hipertensi sebelum dan setelah melaksanakan slow deep breathing menggunakan uji paired t-test dan untuk menganalisis perbedaan perubahan tekanan darah pada kelompok perlakuan dan kelompok kontrol digunakan uji independent t-test dengan bantuan SPSS for windows release 16.0 dengan penentuan taraf signifikansi jika $\mathrm{p}$ value $<\alpha(0,05)$ maka $\mathrm{H}_{\mathrm{o}}$ ditolak dan jika $\mathrm{p}$ value $>\alpha$ $(0,05)$ maka $\mathrm{H}_{\mathrm{o}}$ diterima.

\section{HASIL PENELITIAN}

Hasil pengumpulan data primer dan data sekunder terhadap responden dapat diuraikan sebagai berikut:

\section{Karakteristik Responden}

Tabel 1. Distribusi Responden Berdasarkan Usia, Jenis Kelamin dan Riwayat Hipertensi di Puskesmas Ubung Lombok Tengah, April 2018.

\begin{tabular}{lcc}
\hline Usia & Jumlah & Persentase (\%) \\
\hline $55-64$ & 19 & 66,7 \\
\hline$\geq 65$ & 11 & 33,3 \\
\hline Jenis Kelamin & & 40 \\
\hline Laki-Laki & 12 & 60 \\
\hline Perempuan & 18 & \\
\hline Riwayat Hipertensi & & 76,7 \\
\hline Ada & 26 & 23,3 \\
\hline Tidak Ada & 4 & \\
\hline
\end{tabular}

Berdasarkan tabel diatas dapat dilihat bahwa usia responden terbanyak berada pada usia 55-64 tahun dengan persentase $66,7 \%$, jenis kelamin responden terbanyak adalah perempuan dengan 
persentase $60 \%$ dan riwayat hipertensi terbanyak adalah ada riwayat hipertensi dengan persentase $76,7 \%$.

2. Rata-rata Tekanan Darah Responden pada Kelompok Intervensi dan Kelompok Kontrol Sebelum Dilakukan Slow Deep Breathing.

Tabel 2. Rata-Rata Tekanan Darah Responden Kelompok Intervensi dan Kelompok Kontrol Sebelum Dilakukan Senam Di Puskesmas Ubung Lombok Tengah, April 2018.

\begin{tabular}{clcccc}
\hline Kelompok & $\begin{array}{c}\text { Tekanan } \\
\text { Darah }\end{array}$ & $\begin{array}{c}\text { Rata- } \\
\text { Rata }\end{array}$ & $\begin{array}{c}\text { Standar } \\
\text { Deviasi }\end{array}$ & $\begin{array}{c}\text { Nilai } \\
\text { Minimum }\end{array}$ & $\begin{array}{c}\text { Nilai } \\
\text { Maksimum }\end{array}$ \\
\hline \multirow{2}{*}{ Intervensi } & Sistolik & 151,33 & 9,904 & 140 & 170 \\
\cline { 2 - 6 } & Diastolik & 96,00 & 8,281 & 90 & 110 \\
\hline \multirow{2}{*}{ Kontrol } & Sistolik & 157,33 & 14,376 & 140 & 180 \\
\cline { 2 - 6 } & Diastolik & 98,67 & 9,155 & 90 & 110 \\
\hline
\end{tabular}

Berdasarkan tabel diatas dapat dilihat bahwa rata-rata tekanan darah baik untuk sistolik maupun diastolik pada kelompok kontrol sedikit lebih tinggi $(157,33$ dan 98,67$)$ dibandingkan rata-rata tekanan darah pada kelompok intervensi $(151,33$ dan 96,00) dengan nilai maksimum sistolik lebih tinggi 10 poin.

3. Rata-rata Tekanan Darah Responden pada Kelompok Intervensi dan Kelompok Kontrol Setelah Dilakukan Slow Deep Breathing.

Tabel 3. Rata-Rata Tekanan Darah Responden Kelompok Intervensi dan Kelompok Kontrol Setelah Dilakukan Senam dan Diberikan Latihan Slow deep Breathing Di Puskesmas Ubung Lombok Tengah, April 2018.

\begin{tabular}{llcccc}
\hline Kelompok & $\begin{array}{c}\text { Tekanan } \\
\text { Darah }\end{array}$ & $\begin{array}{c}\text { Rata- } \\
\text { Rata }\end{array}$ & $\begin{array}{c}\text { Standar } \\
\text { Deviasi }\end{array}$ & $\begin{array}{c}\text { Nilai } \\
\text { Minimum }\end{array}$ & $\begin{array}{c}\text { Nilai } \\
\text { Maksimum }\end{array}$ \\
\hline Intervensi & Sistolik & 136,00 & 10,556 & 120 & 150 \\
\cline { 2 - 6 } & Diastolik & 85,33 & 8,338 & 70 & 100 \\
\hline Kontrol & Sistolik & 152,67 & 13,345 & 130 & 170 \\
\cline { 2 - 6 } & Diastolik & 95,33 & 9,155 & 80 & 110 \\
\hline
\end{tabular}

Berdasarkan tabel diatas dapat dilihat bahwa rata-rata tekanan darah lansia hipertensi pada kelompok intervensi lebih rendah dari rata-rata tekanan darah pada kelompok control baik untuk sistolik maupun diastolik. Pada kelompok intervensi, rata-rata tekanan darahnya sudah menjadi normal setelah perlakuan. Untuk nilai minimum dan nilai maksimum tekanan darah lansia hipertensi pada kelompok intervensi jauh lebih rendah dibandingkan pada kelompok control baik untuk sistolik maupun diastolik. 
4. Analisis Pengaruh Slow Deep Breathing terhadap Tekanan Darah Lansia Hipertensi di Puskesmas Ubung Lombok Tengah.

Tabel 4. Hasil Uji Paired T-Test dan Independent T-test Pengaruh Slow Deep Breathing Terhadap Tekanan Darah Lansia Hipertensi di Puskesmas Ubung Lombok tengah Tahun 2018

\begin{tabular}{|c|c|c|c|c|c|c|}
\hline & \multirow[t]{2}{*}{ Kelompok } & \multirow[t]{2}{*}{$\begin{array}{c}\text { Tekanan } \\
\text { Darah }\end{array}$} & \multicolumn{2}{|c|}{ Rata-Rata } & \multirow[t]{2}{*}{$\mathbf{N}$} & \multirow[t]{2}{*}{ P value } \\
\hline & & & Pre & Post & & \\
\hline \multirow{4}{*}{$\begin{array}{l}\text { kan perhitungan } \\
\text { SPSS } 16.0 \text { diatas }\end{array}$} & Intervensi & Sistol & 151,33 & 136,00 & 15 & .000 \\
\hline & & Diastol & 96,00 & 85,33 & 15 & .000 \\
\hline & Kontrol & Sistol & 157,33 & 152,67 & 15 & .004 \\
\hline & & Diastol & 98,67 & 95,33 & 15 & .096 \\
\hline uji paired t-test & P value & Sistol & & & & .001 \\
\hline pretest dan & & Diastol & & & & .004 \\
\hline
\end{tabular}

posttest tekanan darah sistol kelompok intervensi didapatkan nilai signifikan ( $\rho$ value) 0.001 sehingga $\mathrm{H}_{\mathrm{o}}$ ditolak dan disimpulkan bahwa terdapat pengaruh slow deep breathing terhadap tekanan darah tekanan darah sistol pada kelompok intervensi dan hasil uji paired t-test pretest dan posttest tekanan darah diastol kelompok intervensi didapatkan nilai signifikan ( $\rho$ value) 0.004 sehingga $\mathrm{H}_{\mathrm{o}}$ ditolak dan disimpulkan bahwa terdapat pengaruh slow deep breathing terhadap tekanan darah diastol pada kelompok intervensi.

\section{PEMBAHASAN}

1. Identifikasi Tekanan Darah Responden Sebelum Latihan slow deep breathing pada Kelompok Intervensi dan Kelompok Kontrol.

Rata-rata nilai tekanan darah sistol pada kelompok intervensi yaitu $151,33 \mathrm{mmHg}$ dengan standar deviasi 9,904 mmHg dan nilai minimum $140 \mathrm{mmHg}$ serta nilai maksimum $170 \mathrm{mmHg}$. Kemudian rata-rata nilai tekanan darah diastol pada kelompok intervensi yaitu 96,00 $\mathrm{mmHg}$ dengan standar deviasi 8,281 mmHg dan nilai minimum $90 \mathrm{mmHg}$ serta nilai maksimum $110 \mathrm{mmHg}$. Sedangkan ratarata nilai tekanan darah sistol pada kelompok kontrol yaitu $157,33 \mathrm{mmHg}$ dengan standar deviasi 14,376 mmHg dan nilai minimum $140 \mathrm{mmHg}$ serta nilai maksimum $180 \mathrm{mmHg}$. Kemudian rata-rata nilai tekanan darah diastol pada kelompok kontrol yaitu 98,67 mmHg dengan standar deviasi 9,155 mmHg dan nilai minimum $90 \mathrm{mmHg}$ serta nilai maksimum $110 \mathrm{mmHg}$.

Didapatkannya perbedaan tekanan darah dari setiap responden karena ada beberapa faktor yang mempengaruhi besarnya tekanan darah setiap orang. Hal ini sesuai dengan teori yang menyatakan bahwa terdapat faktor-faktor yang mempengaruhi besarnya tekanan darah setiap orang yaitu terdiri dari faktor resiko yang tidak dapat dikendalikan seperti usia, jenis kelamin, etnis/ras dan keturunan sedangkan faktor resiko yang dapat dikendalikan yaitu kegemukan, stres, merokok, kurang olahraga, konsumsi alkohol, konsumsi garam berlebihan, dan kolesterol (Depkes RI, 2006). 
Usia responden dalam penelitian ini berada dalam rentang usia 55-64 tahun dan $\geq 65$ tahun. Hal ini sesuai dengan teori yang menyatakan kejadian hipertensi semakin meningkat seiring bertambahnya umur, tekanan darah akan meningkat terutama tekanan darah sistolik, sedangkan tekanan darah diastolik pada mulanya meningkat, tetapi pada usia pertengahan akan menetap atau akan menurun sejalan dengan pengerasan pembuluh darah (Kurniadi \& Ulfa, 2015). Penyakit hipertensi paling dominan terjadi pada kelompok umur 31-55 tahun, dikarenakan sering bertambahnya usia. Pada umumnya, hipertensi menyerang pria pada usia di atas 31 tahun, sedangkan pada wanita terjadi setelah usia 45 tahun (menopause) (Dalimartha, 2008).

Faktor yang kedua yaitu jenis kelamin, berdasarkan hasil penelitian ini sebagian besar responden berjenis kelamin perempuan sebanyak 18 orang. Hal ini sesuai dengan teori yang menyatakan pria lebih banyak mengalami hipertensi ketika usia pertengahan, sedangkan wanita lebih banyak mengalami hipertensi ketika memasuki usia lanjut (Tambayong, 2010). Pria diduga memiliki gaya hidup yang cenderung dapat meningkatkan tekanan darah dibandingkan dengan perempuan. Akan tetapi setelah memasuki menopause, prevalensi hipertensi pada perempuan meningkat. Wanita memiliki resiko lebih tinggi untuk menderita hipertensi. Produksi hormon estrogen menurun saat menopause, wanita kehilangan efek menguntungkannya sehingga tekanan darah meningkat (Benson, 2012).

Faktor selanjutnya yaitu faktor genetik, terdapat sebagian besar responden memiliki riwayat hipertensi sebanyak 26 orang. Hal ini sesuai dengan teori yang menyatakan faktor genetik pada keluarga tertentu akan menyebabkan keluarga tersebut mempunyai resiko menderita hipertensi. Individu yang memiliki orang tua dengan hipertensi memiliki resiko dua kali lebih besar untuk menderita hipertensi ketimbang individu yang tidak mempunyai keluarga dengan riwayat hipertensi. Selain itu, individu normotensi yang memiliki orang tua yang mengidap hipertensi memiliki reaktivitas vaskuler yang lebih tinggi terhadap stress mental maupun fisik dibanding individu dan orang tua yang memiliki tekanan darah normal. Hal ini berkaitan dengan timbulnya hipertensi di kemudian hari (Kurniadi \& Ulfa, 2015).

Tekanan darah yaitu jumlah gaya yang diberikan oleh darah di bagian dalam arteri saat darah dipompa ke seluruh sistem peredaran darah. Tekanan darah tidak pernah konstan, tekanan darah dapat berubah drastis dalam hitungan detik, menyesuaikan diri dengan tuntutan pada saat itu (Benson, 2012). Meningkatnya tekanan darah di dalam arteri bisa terjadi melalui beberapa cara yaitu jantung memompa lebih kuat, sehingga mengalirkan darah pada setiap denyut jantung dipaksa untuk melalui pembuluh yang sempit dari pada biasanya dan menyebabkan naiknya tekanan. Inilah yang terjadi pada usia lanjut, dimana dinding arterinya telah menebal dan kaku karena arteriosklierosis (Triyanto, 2014). Tekanan darah tinggi atau hipertensi adalah keadaan dimana saat pembuluh darah tidak lagi elastis. Kondisi ini menyebabkan tekanan pada pembuluh darah meningkat. Tekanan yang terlalu tinggi dapat merobek pembuluh dan mengakibatkan terjadinya pendarahan atau komplikasi lainnya (Wong, 2011). Peneliti berpendapat bahwa penatalaksanaan yang tidak tepat oleh penderita hipertensi 
dengan tidak melakukan upaya perawatan diri yang benar, akan berdampak kepada peningkatan tekanan darah yang berkepanjangan dan akan merusak pembuluh darah yang ada di sebagian besar tubuh. Hali ini dibuktikan dengan hasil penelitian Susan A. Oliveria, et al. (2004) bahwa 50\% sampai $75 \%$ pasien telah didiagnosa hipertensi dan sedang mendapatkan pengobatan tidak melakukan upaya perawatan diri untuk mengontrol tekanan darah secara teratur.

2. Identifikasi Tekanan Darah Responden Setelah Latihan slow deep breathing pada Kelompok Intervensi dan Kelompok Kontrol.

Rata-rata nilai tekanan darah sistol pada kelompok intervensi yaitu 136,00 mmHg dengan standar deviasi 10,556 mmHg dan nilai minimum $120 \mathrm{mmHg}$ serta nilai maksimum $150 \mathrm{mmHg}$. Kemudian rata-rata nilai tekanan darah diastol pada kelompok intervensi yaitu 85,33 $\mathrm{mmHg}$ dengan standar deviasi 8,338 mmHg dan nilai minimum $70 \mathrm{mmHg}$ serta nilai maksimum $100 \mathrm{mmHg}$. Sedangkan ratarata nilai tekanan darah sistol pada kelompok kontrol yaitu 152,67 mmHg dengan standar deviasi 13,345 mmHg dan nilai minimum $130 \mathrm{mmHg}$ serta nilai maksimum $170 \mathrm{mmHg}$. Kemudian rata-rata nilai tekanan darah diastol pada kelompok kontrol yaitu 95,33 mmHg dengan standar deviasi 9,155 $\mathrm{mmHg}$ dan nilai minimum $80 \mathrm{mmHg}$ serta nilai maksimum $110 \mathrm{mmHg}$.

Penurunan tekanan darah lebih banyak pada kelompok intervensi yang mendapatkan perlakuan berupa senam dan slow deep breathing, dibandingkan kelompok kontrol yang hanya mendapatkan senam saja. Slow deep breathing memberikan efek kepada sistem saraf dan mempengaruhi pengaturan tekanan darah. Slow deep breathing menurunkan aktivitas saraf simpatis melalui peningkatan central inhibitory rythms yang akan berdampak pada penurunan output simpatis. Penurunan output simpatis akan menyebabkan penurunan pelepasan epinefrin yang ditangkap oleh reseptor alfa sehingga mempengaruhi otot polos pembuluh darah. Otot polos vaskular mengalami vasodilatasi yang akan menurunkan tahanan perifer dan menyebabkan penurunan tekanan darah. Oleh karena itu latihan slow deep breathing dapat digunakan sebagai terapi nonfarmakolgis pada penderita hipertensi baik yang mengkonsumsi obat ataupun tidak mengkonsumsi obat (Fatimah \& Setiawan, 2009).

Berdasarkan hasil penelitian ini peneliti berpendapat bahwa teknik relaksasi dengan bernafas yang dalam secara rutin melancarkan peredaran darah kemudian membantu penurunan tekanan darah menjadi normal. Seperti yang diketahui, pembuluh darah yang tersumbat membuat tekanan darah meningkat, sehingga dapat menyebabkan resiko terjadinya komplikasi. Adapun pemberian relaksasi slow deep breathing berarti telah memberikan penanganan alternative pada pasien secara non farmakologi, selain dengan olahraga atau senam dan mengkonsumsi obat-obatan dapat memberikan pengetahuan pada pasien dalam mengatasi tekanan darah pada pasien hipertensi.

Hasil penelitian pada kelompok kontrol ini sejalan dengan penelitian yang dilakukan oleh Sulistyowati (2010), dimana ada hubungan antara aktifitas olahraga dengan kejadian hipertensi, dimana responden yang kebiasaan olahraganya kurang mempunyai risiko terkena hipertensi sebesar 2,38 kali lebih besar dibandingkan responden yang kebiasaan olahraganya baik. Penelitian pada kelompok intervensi ini sejalan dengan hasil penelitian yang dilakukan oleh Anderson (2010) tentang 
pengaruh latihan rutin slow deep breathing terhadap tekanan darah dengan rata-rata tekanan darah sistolik posttest adalah $153 \mathrm{mmHg}$ dan tekanan darah diastolik posttest $96 \mathrm{mmHg}$.

3. Pengaruh Slow Deep Breathing terhadap Tekanan Darah Lansia Hipertensi di Puskesmas Ubung, Lombok Tengah

Hasil Penelitian menunjukkan bahwa ada perubahan pretest dan posttest tekanan darah sistol kelompok intervensi didapatkan nilai signifikansi ( $\rho$ value) 0.001 sehingga $\mathrm{H}_{\mathrm{o}}$ ditolak dan disimpulkan bahwa terdapat pengaruh slow deep breathing terhadap tekanan darah sistol pretest dan posttest pada kelompok intervensi, sedangkan tekanan darah diastol pada kelompok intervensi didapatkan nilai signifikansi ( $\rho$ value) 0.004 sehingga $\mathrm{H}_{0}$ ditolak dan disimpulakan terdapat pengaruh slow deep breathing terhadap tekanan darah diastol pretest dan posttest pada kelompok intervensi. Dari hasil perhitungan ini, terdapat pengaruh slow deep breathing terhadap tekanan darah lansia hipertensi di Puskesmas Ubung Lombok Tengah.

Berdasarkan penelitian Amandeep (2015), latihan slow deep breathing dianggap efek yang paling bermanfaat dalam mengurangi tekanan darah pada pasien hipertensi. Studi terbaru menunjukkan bahwa pasien yang rutin melakukan slow deep breathing telah berhenti mengonsumsi obat antihipertensi dan berpaling pada latihan. Berbagai penelitian mengenai efek slow deep breathing ditemukan bahwa ada penurunan yang signifikan dalam tekanan darah setelah berolahraga.

Penelitian tentang slow deep breathing yang dilakukan oleh Critchley tahun 2015 menunjukkan hasil slow deep breathing dapat mempengaruhi cortex cerebri dan bagian medulla yang positif berhubungan dengan relaksasi pada sistem saraf yang dapat mempengaruhi mekanisme penurunan tekanan darah. Pernafasan yang lambat dan dalam mampu meningkatkan kadar oksigen di dalam tubuh merangsang kemoreseptor tubuh. Rangsangan pada kemoreseptor tubuh dapat memberikan respon vasodilatasi pembuluh darah kemudian menurunkan tekanan vaskular sehingga tekanan darah turun (Fatimah \& Setiawan, 2009).

Hasil penelitian ini juga didukung oleh penelitian yang terdahulu pada penelitian yang dilakukan oleh Yanti (2016) tentang pengaruh slow deep breathing terhadap tekanan darah pada penderita hipertensi. Penelitian tersebut memiliki kesimpulan bahwa adanya pengaruh pemberian slow deep breathing terhadap tekanan darah pada penderita hipertensi. Berdasarkan hasil penelitian ini peneliti berpendapat bahwa relaksasi slow deep breathing jika dilakukan dengan benar akan memberikan pengaruh terhadap tekanan darah lansia hipertensi. Hasil wawancara, responden juga mengatakan lebih tahu bagaimana cara untuk menurunkan tekanan darah selain senam dan minum obat. Hambatan yang didapat peneliti saat melakukan penelitian adalah tidak dapat memantau pola hidup responden dan pelaksanaan slow deep breathing yang dilakukan responden, karena pola hidup responden tidak teratur dan responden tidak selalu melakukan latihan slow deep breathing karena kesibukan masingmasing.

\section{KESIMPULAN}


Kesimpulan dalam penelitian ini adalah bahwa latihan slow deep breathing memiliki pengaruh terhadap tekanan darah lansia Hipertensi di Puskesmas Ubung, Lombok Tengah. Berdasarkan hasil penelitian ini maka disarankan bahwa slow deep breathing dimasukkan juga ke dalam program pengendalian hipertensi yang dilakukan secara terjadwal di Puskesmas.

\section{DAFTAR PUSTAKA}

Adinil, H. 2004. Penatalaksanaan Hipertensi Secara Komprehensif. Jurnal Kedokteran Muhammadiyah 2 (2)

Almatsier, S. 2010. Penuntun Diet, Edisi Baru. Gramedia: Jakarta.

Amandeep K., Preksha S. M., Dirya S. 2015. Effectiveness of Abdominal Breathing Exercise On Blood Pressure Among Hypertensive Patients. Internasional Journal Of Therapeutic Applications, Volume 24, 2015. 39-49

Azizah, M. Lilik. 2015. Keperawatan Lanjut Usia Edisi 1. Yogyakarta: Graha Ilmu

Benson, Herbert dkk. 2012. Menurunkan Tekanan Darah. Gramedia: Jakarta.

Breathesy. 2006. Blood Pressure reduction : Frequently asked question, http:www.control your bloodpressure.com/faq.html, diakses tanggal 9 Januari 2011.

Buckman, Robert dan Pasty Westcott. 2010.Apa Yang Seharusnya Anda Ketahui Tentang Tekanan Darah Tinggi. Yogyakarta: PT. Citra Aji Parama

Cohen, Louis, Lawrence Manion, dan Keith Morrison. 2007. Research Methods in Education, Sixth Edition. London: Routledge Falmer.

Corwin, Elizabet J. 2009. Buku Saku Patofisiologi. Jakarta: EGC

Delimatha, S. 2008. Hipertensi. Jakarta: Penebar Plus

Depkes RI. 2006. Pharmaceutical Care Untuk Hipertensi. Departemen Kesehatan RI: Jakarta

Dewi, S. dan Famila. 2010. Hidup Bahagia Bersama Hipertensi. Jakarta: A Plus Books

Dharma, Kelana Kusuma. 2011. Metodologi Penelitian Keperawatan Panduan Melaksanakan dan Menerapkan Hasil Penelitian. Trans Info Media. Jakarta.

Geng, A., \& Ikiz, A. 2009. Effect of Deep Breathing Exercises on oxygenatipn after head and neck surgery. Elsevier Mosby.

Kementerian Kesehatan RI. 2014. INFODATIN.Pusat Data Dan Informasi Kementerian Kesehatan RI.HIPERTENSI.Jakarta.

Kementrian Kesehatan RI (Kemenkes RI). 2013. Riset Kesehatan Dasar. Diakses melalui: //www.Kemenkesri.go.id//riskesdas.doc//pdf.

Kurniadi, Helmanu \& Ulfa Nurrahmani. 2015. Stop Diabetes Hipertensi Kolesterol Tinggi Jantung Koroner. Yogyakarta: Istana Media

Kushariyadi. 2009. Asuhan Keperawatan Pada Klien Lanjut Usia. Jakarta : Salemba Medika.

Larsson, B., \& Jane, C. 2004. Relaxation Treatment of Adolescent Headache Sufferers : Results From a School-Based Replication Series, diakses tanggal 18 November 2017. http://web.ebscohost.com

Martiani, A \& Rosa Lelyana. 2012. Faktor Risiko Hipertensi Ditinjau Dari Kebiasaan Minum Kopi: Journal of Nutrition College, Volume 1, Nomor 1, Tahun 2012, Halaman 78-85 Online, http://ejournals1. undip.ac.id/index.php/jnc.

Martini, F. 2006. Fundamentals of Anatomy \& Physiology. Seventh Edition, Pearson, Benjamin Cummings

Maryam, R.S.dkk. 2008. Mengenal usia lanjut dan perawatannya. Salemba Medika. Jakarta.

Muttaqin, Arif. 2009. Buku Ajar Asuhan Keperawatan Dengan Gangguan Sistem Kardiovaskuler. Jakarta: Salemba Medika.

Notoatmodjo, Soekidjo. 2012. Metodologi Penelitian Kesehatan. Jakarta: Rineka Cipta.

Nugroho, W. 2012. Gerontik dan Geriatrik. Jakarta : Penerbit Buku Kedeokteran.

Nursalam, 2016. Metodelogi Penelitian Ilmu Keperawatan Pendekatan Praktis. Edisi 4. Salemba Medika. Jakarta

Palmer, Anna. 2007. Simpel Guide Tekanan Darah Tinggi. Erlangga: Jakarta 
Potter, A.P., \& Perry, A. 2006. Buku Ajar Fundamental Keperawatan Edisi 4 Volume 1. Jakarta : EGC.

Price, S. A. dan Wilson, L. M. 2006. Patofisiologi: Konsep Klinis Proses penyakit, Edisi 6, Volume 1. Jakarta: EGC

Sepdianto, T.C. Nurachmah, E., \& Gayatri, D. 2010. Penurunan Tekanan Darah dan Kecemasan Melalui Latihan Slow Deep Breathing Pada Pasien Hipertensi Primer. Jurnal Keperawatan Indonesia:13 (1), Hal 37-40. https://Scholar.google.co.id/Jki.ui.ac.id.

Setiadi. 2007. Konsep dan Penulisan Riset Keperawatan. Yogyakarta: Graha Ilmu

Shanty, Meita. 2011. Silent Killer Diseases (Penyakit yang diam-diam mematikan) Yogyakarta: Javalitera

Susilo, Yekti \& Ari Wulandari. 2011. Cara Jitu Mengatasi Hipertensi. Yogyakarta: ANDI

Sugiyono. 2010. Metodologi Penelitian. Bandung: Alfabeta.

Sugiyono. 2015. Statistika Non Parametris Untuk Penelitian. Bandung: Alfabet.

Sutanto. 2010. CEKAL (Cegah dan Tanggal) Penyakit Modern Hipertensi, Stroke, Jantung, Kolesterol, dan Diabetes. Yogyakarta: ANDI

Sutomo, B. 2009. Menu Sehat Penakluk Hipertensi. Jakarta: De Media Pustaka

Sylvia. 2003. Buku ajar Senam Jantung Sehat. Edisi 1. Yogyakarta: Graha Ilmu

Tambayong, J. 2010. Patofisiologi Keperawatan. Jakarta : EGC

Tarwoto.2011. Pengaruh Latihan Slow Deep Breathing Terhadap Intensitas

Nyeri Kepala Akut Pada Pasien Cedera Kepala Ringan. Universitas Indonesia

Triyanto, Endang. 2014. Pelayanan Keperawatan bagi Penderita Hipertensi Secara Terpadu. Yogyakarta: Graha Ilmu.

Vitahealth. 2010. Hipertensi. Jakarta: Gramedia Pustaka Utama

Wahyunita, V. D. \& Fitrah. 2010. Memahami Kesehatan pada Lansia. Jakarta Timur: Trans Info Media

Widharto, 2009. Bahaya Hipertensi. Jakarta : Sunda Kelapa Pustaka

Wijayakusuma, S. 2000. Gaya Hidup Sehat Penderita Hipertensi. Bogor: CV. Graha satya.

Wong, Fery M. 2011. Panduan Lengkap Pijat Cetakan 1. Jakarta: Penebar Plus. https://books.google.co.id

World Health Organization. 2015. Clinical Guiddelines For The Management of Hypertension. Cairo: World Health Organization. Yogyakarta.

Yanti, N. 2016. Pengaruh Slow Deep Breathing Terhadap Tekanan Darah Pada Penderita Hipertensi di Wilayah Kerja Puskesmas 1 Denpasar Timur. Nurscope. Jurnal Keperawatan dan Pemikiran Ilmiah. 2 (4). 1-10.

Yuliati, Sufrida dan Maloedyn Sitanggang.2006. 30 Ramuan Penakluk Hipertensi. Jakarta: Agro Media Pustaka 